\title{
REFERENSI PENUGASAN TENAGA TEKNISI PADA PENANGANAN VARIAN KERUSAKAN MENGGUNAKAN DECISION SUPPORT SYSTEM
}

\author{
Aries Setiawan ${ }^{1}$, Juli Ratnawati ${ }^{2}$, Adi Prihandono ${ }^{3}$ \\ ${ }^{1}$ Fakultas IImu Komputer, Universitas Dian Nuswantoro \\ Semarang, Indonesia, email : arissetya_005@dsn.dinus.ac.id \\ ${ }^{2}$ Fakultas Ekonomi dan Bisnis, Universitas Dian Nuswantoro \\ Semarang, Indonesia, email : juli.ratnawati@dsn.dinus.ac.id \\ ${ }^{3}$ Fakultas Ilmu Komputer, Universitas Dian Nuswantoro \\ Semarang, Indonesia, email : adimsssemarang@gmail.com
}

\section{ARTICLE INFO}

Article history:

Received 21 January 2021

Received in revised form 26 July 2021

Accepted 31 July 2021

Available online 31 July 2021

\begin{abstract}
One type of asset managed by an agency is an asset that has a service life limit, if it is not properly maintained it will affect the quality of use. Maintenance can be in the form of routine and incidental maintenance carried out by technicians. Each technician has different abilities, so the assignment should be based on objectivity. The high quantity of maintenance on all assets in an agency and often lack of attention to the division of tasks on all technicians resulted in some technicians having to accept maintenance assignments on assets that were not in accordance with their fields. The right steps were taken to support the decision to refer technicians to an asset maintenance process using the $K$ Nearest Neigbor method. The final result shows that the percentage of occurrences of referenced names occupies the highest percentage, namely $66 \%$ with a value of $k=3$, so that $k=3$ is suitable for the process of reference for technicians.
\end{abstract}

Keywords: Reference, Assignment, technician, K-Nearest Neigbor

\section{Pendahuluan}

Salah satu jenis aset yang dikelola oleh sebuah instansi adalah peralatan yang mempunyai batas umur pakai, jika perawatannya tidak tepat maka berakibat pada kualitas pemakaian [1].

Perawatan bisa berupa servis rutin dan insidensial yang perawatannya dilakukan oleh tenaga teknisi yang mempunyai kewenangan untuk menyiapkan, memperbaiki serta merawat sarana maupun prasarana [2]

Kemampuan dari setiap teknisi belum tentu mampu mengimbangi tingkat kerusakan pada setiap aset juga berbeda-beda. Begitu juga aset baru belum tentu mempunyai masa usia pemakaian yang panjang, yang berarti varian kerusakan juga sangat banyak. Pemilihan tenaga teknisi yang tepat akan memberikan layanan perawatan yang efektif [3].

Pengalaman seorang teknisi dipengaruhi oleh tingkat keahlian serta kuantitas dalam mengatasi kerusakan pada beberapa aset. Kenyataan dilapangan sering menunjukkan bahwa setelah sebuah peralatan diperbaiki, kondisinya menjadi lebih buruk dari sebelumnya, hal ini dikarenakan tingkat analisa kerusakan yang lemah dari seorang teknisi.

Divisi teknisi, yang dipimpin oleh seorang kepala teknisi membagi tugas dari masingmasing teknisi yang berada dibawahnya. Pemberian tugas berdasarkan pada unsur subyektivitas 
tidak akan mampu memberikan hasil layanan yang baik pada proses perbaikan yang diminta oleh masing-masing divisi [4], karena pemilihan berdasarkan subyektivitas belum tentu mengarah pada tingkat kerusakan alat. Seorang kepala teknisi harus mampu memahami tingkat keahlian dari masing-masing teknisi.

Sebuah upaya untuk menentukan tenaga teknisi yang sesuai dengan tingkat perawatan aset adalah dengan melakukan perhitungan menggunakan metode $K$-Nearest Neigbor berdasarkan nilai variabel-variabel yang digunakan. Hal ini sebagai nilai kebaharuan dalam mendukung keputusan yang obyektif terhadap referensi tenaga teknisi yang akan menangani setiap perawatan aset yang ada pada instansi

Pada Penelitian [5], K-Nearest Neighbor mampu menghasilkan akurasi 96\% dan waktu eksekusi pada KNN 0,01428 dalam menentukan klasifikasi KIS untuk warga miskin, pada implementasinya metode ini lebih fleksible dan mempercepat proses penyeleksian dengan didasarkan pada kedekatan pada data sample sebelumnya [6]

\section{Metode Penelitian}

\subsection{Tahapan Penelitian}

Tahapan penelitian yang digunakan :

1. Mengidentifikasi masalah, tahapan ini mengidentifikasi tentang seberapa penting sebuah sistem pendukung keputusan digunakan dalam referensi penugasan tenaga teknisi

2. Pengumpulan Data, Data yang dipakai dalam penelitian ini adalah data dari sejumlah teknisi dari kepala bagian teknisi perguruan tinggi.

3. Penerapan Metode, melakukan perhitungan dengan metode $K$-Nearest Neighbor dengan mengikuti setiap tahapannya

4. Analisis, melakukan analisis dengan membandingkan pemakaian nilai $\mathrm{k}$ pada perhitungan metode

\subsection{Metode K-Nearest Neighbor}

K-Nearest memiliki ide dasar mengelompokkan data sample terdekat dengan cara mengidentifikasi data uji [7].

Sebagai salah satu metode klasifikasi [8], K-Nearest Neighbor memiliki diagram tahapan sebegai berikut [9]:

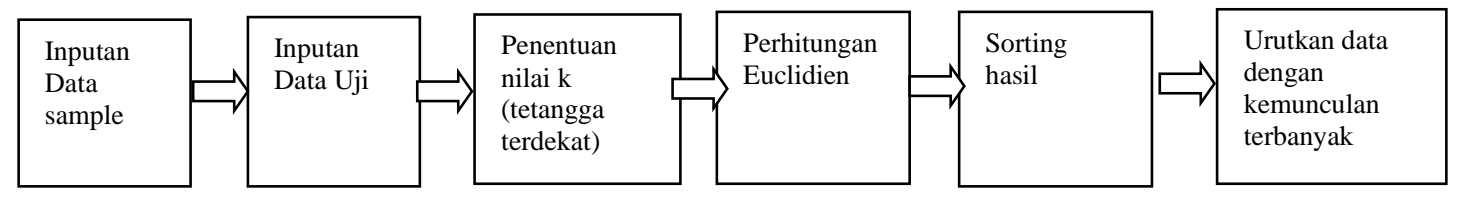

Gambar 1. Tahapan K-Nearest Neigbor

Kemunculan terbanyak dari data sample merupakan urutan pilihan tertinggi [10]

Dalam perhitungannya, metode K-Nearest Neighbor menggunakan pendekatan sebagai berikut [11].

$$
d(a, b)=\sqrt{\sum_{b=1}^{n}(X a-X b)^{2}}
$$

d(a,b) merupakan jarak tetangga terdekat atau nilai Euclidean yang diperoleh dari data sample dan data uji. Jumlah data sample dianyatakan dengan $\mathrm{n}$, nilai dari data uji dinyatakan dengan Xa dan nilai data sample dinyatakan dengan $\mathrm{Xb}[12]$. 


\section{Hasil dan Analisis}

\subsection{Variabel Penilaian}

Beberapa variabel penilaian yang digunakan dalam implementasi referensi penugasan untuk teknisi adalah

Tabel 1. Variabel Penilaian

\begin{tabular}{|c|c|c|}
\hline Jenis Variabel & Pilihan & $\begin{array}{l}\text { Konversi } \\
\text { Nilai }\end{array}$ \\
\hline \multirow{5}{*}{ Tingkat pendidikan } & SMA & 1 \\
\hline & SMK dengan jurusan tidak sesuai & 2 \\
\hline & SMK dengan jurusan sesuai & 3 \\
\hline & SARJANA dengan jurusan tidak sesuai & 4 \\
\hline & SARJANA dengan jurusan sesuai & 5 \\
\hline \multirow[t]{4}{*}{ Lama Kerja } & Kurang dari 3 tahun & 1 \\
\hline & Antara 3 sampai 5 tahun & 2 \\
\hline & Antara 6 sampai 10 tahun & 3 \\
\hline & Diatas 10 tahun & 4 \\
\hline \multirow[t]{3}{*}{ Bidang Keahlian } & Arus kuat & 1 \\
\hline & $\mathrm{AC}$ & 2 \\
\hline & Arus Lemah & 3 \\
\hline \multirow[t]{6}{*}{ Jenis Kerusakan } & Arus Kuat (JK sedang) & 1 \\
\hline & AC (JK sedang) & 2 \\
\hline & Arus Lemah (JK sedang) & 3 \\
\hline & Arus Kuat (JK kuat) & 4 \\
\hline & AC (JK Kuat) & 5 \\
\hline & Arus Lemah (JK kuat) & 6 \\
\hline \multirow[t]{5}{*}{ Usia } & Kurang dari 20 tahun & 1 \\
\hline & Diatas 50 tahun & 2 \\
\hline & Antara 21 sampai 30 tahun & 3 \\
\hline & Antara 31 sampai 40 tahun & 4 \\
\hline & Antara 40 sampai 50 tahun & 5 \\
\hline Tingkat & Rendah & 1 \\
\hline \multirow[t]{2}{*}{ kerusakan } & Sedang & 2 \\
\hline & Tinggi & 3 \\
\hline \multirow[t]{2}{*}{ Tingkat Ketuntasan } & Tidak Tuntas & 1 \\
\hline & Tuntas & 2 \\
\hline
\end{tabular}

\subsection{Analisis}

Beberapa hal yang perlu disiapkan dalam tahapan metode ini adalah ini adalah penyiapan sejumlah data sample dan penyediaan data uji [13]. Untuk selanjutnya pencarian euclidien [14].

a. Data Sample 
Data sample diambil dari data kompetensi dari tiap-tiap teknisi yang sudah dikonversi sesuai pada tabel 1.

Tabel 2. Data Sample

\begin{tabular}{|c|c|c|c|c|c|c|c|c|}
\hline No. & $\begin{array}{l}\text { Tk. } \\
\text { Pendidikan }\end{array}$ & $\begin{array}{l}\text { Lama } \\
\text { Kerja }\end{array}$ & $\begin{array}{l}\text { Bidang } \\
\text { Keahlian }\end{array}$ & $\begin{array}{l}\text { Jenis } \\
\text { Kerusakan }\end{array}$ & Usia & $\begin{array}{l}\text { Tingkat } \\
\text { Kerusakan }\end{array}$ & $\begin{array}{l}\text { Tk. } \\
\text { Ketuntasan }\end{array}$ & $\begin{array}{l}\text { Nama } \\
\text { Teknisi }\end{array}$ \\
\hline 1 & 1 & 2 & 3 & 1 & 3 & 2 & 2 & Agus \\
\hline 2 & 5 & 4 & 1 & 1 & 2 & 3 & 2 & Danu \\
\hline 3 & 3 & 4 & 3 & 1 & 5 & 3 & 2 & Arifin \\
\hline 4 & 3 & 4 & 2 & 1 & 5 & 3 & 1 & Suryanto \\
\hline 5 & 3 & 4 & 2 & 1 & 5 & 3 & 2 & sulistyo \\
\hline 6 & 3 & 3 & 2 & 1 & 4 & 3 & 1 & Surono \\
\hline 7 & 3 & 4 & 1 & 1 & 5 & 3 & 1 & Ismadi \\
\hline 8 & 3 & 4 & 2 & 2 & 5 & 1 & 1 & sulistyo \\
\hline 9 & 5 & 4 & 1 & 2 & 2 & 2 & 2 & Danu \\
\hline 10 & 3 & 4 & 3 & 2 & 5 & 2 & 2 & Arifin \\
\hline 11 & 3 & 4 & 2 & 2 & 5 & 2 & 2 & Suryanto \\
\hline 12 & 3 & 3 & 2 & 2 & 4 & 2 & 2 & Surono \\
\hline 42 & 1 & 2 & 3 & 6 & 3 & 3 & 1 & Agus \\
\hline
\end{tabular}

\section{b.Data Uji}

Berdasarkan data uji berikut, selanjutnya akan ditentukan nama teknisi yang sesuai untuk menangani perbaikan pada urutan data ke-43 dengan perhitungan metode K-Nearest Neighbor.

Tabel 3. Data Uji

\begin{tabular}{rlrllllll}
\hline & Tk. & Lama & Bidang & Jenis & & Tingkat & Tk. & Nama \\
No. & Pendidikan & Kerja & Keahlian & Kerusakan & Usia & Kerusakan & Ketuntasan & Teknisi \\
\hline & SMK & & & & & & & \\
& dengan & & & Arus Kuat & & & & \\
& jurusan & 4 & Arus & $(\mathrm{JK}$ & 42 & & & \\
43 & sesuai & tahun & Lemah & Sedang) & tahun & Sedang & Tuntas & $?$ \\
\hline
\end{tabular}

Selanjutnya konversikan data uji pada tabel 3 sehingga diperoleh hasil sebagai berikut

Tabel 4. Tabel Konversi Data Uji

\begin{tabular}{rlrllrlll}
\hline & Tk. & Lama & Bidang & Jenis & & Tingkat & Tk. & Nama \\
No. & Pendidikan & Kerja & Keahlian & Kerusakan & Usia & Kerusakan & Ketuntasan & Teknisi \\
\hline 43 & 3 & 2 & 3 & 1 & 5 & 2 & 2 & $?$ \\
\hline
\end{tabular}

c. Perhitungan Euclidien Distance

Euclidien Distance diperoleh dengan melakukan pemangkatan selisih data uji dengan data sample pada setiap baris datanya [15]

Tabel 5. Perhitungan Euclidian 


\begin{tabular}{|c|c|c|c|c|c|c|c|c|}
\hline No. & $\begin{array}{l}\text { Tk. } \\
\text { Pendidik } \\
\text { an }\end{array}$ & $\begin{array}{l}\text { Lama } \\
\text { Kerja }\end{array}$ & $\begin{array}{l}\text { Bidang } \\
\text { Keahlian }\end{array}$ & $\begin{array}{l}\text { Jenis } \\
\text { Kerusakan }\end{array}$ & Usia & $\begin{array}{l}\text { Tingkat } \\
\text { Kerusakan }\end{array}$ & $\begin{array}{l}\text { Tk. } \\
\text { Ketuntasan }\end{array}$ & $\begin{array}{l}\text { Nama } \\
\text { Teknisi }\end{array}$ \\
\hline 1 & $(3-1)^{2}$ & $(2-2)^{2}$ & $(3-3)^{2}$ & $(1-1)^{2}$ & $(5-3)^{2}$ & $(2-2)^{2}$ & $(2-2)^{2}$ & Agus \\
\hline 2 & $(3-5)^{2}$ & $(2-4)^{2}$ & $(3-1)^{2}$ & $(1-1)^{2}$ & $(5-2)^{2}$ & $(2-3)^{2}$ & $(2-2)^{2}$ & Danu \\
\hline 3 & $(3-3)^{2}$ & $(2-4)^{2}$ & $(3-3)^{2}$ & $(1-1)^{2}$ & $(5-5)^{2}$ & $(2-3)^{2}$ & $(2-2)^{2}$ & Arifin \\
\hline 4 & $(3-3)^{2}$ & $(2-4)^{2}$ & $(3-2)^{2}$ & $(1-1)^{2}$ & $(5-5)^{2}$ & $(2-3)^{2}$ & $(2-1)^{2}$ & Suryanto \\
\hline 5 & $(3-3)^{2}$ & $(2-4)^{2}$ & $(3-2)^{2}$ & $(1-1)^{2}$ & $(5-5)^{2}$ & $(2-3)^{2}$ & $(2-2)^{2}$ & sulistyo \\
\hline 6 & $(3-3)^{2}$ & $(2-3)^{2}$ & $(3-2)^{2}$ & $(1-1)^{2}$ & $(5-4)^{2}$ & $(2-3)^{2}$ & $(2-1)^{2}$ & Surono \\
\hline 7 & $(3-3)^{2}$ & $(2-4)^{2}$ & $(3-1)^{2}$ & $(1-1)^{2}$ & $(5-5)^{2}$ & $(2-3)^{2}$ & $(2-1)^{2}$ & Ismadi \\
\hline 8 & $(3-3)^{2}$ & $(2-4)^{2}$ & $(3-2)^{2}$ & $(1-2)^{2}$ & $(5-5)^{2}$ & $(2-1)^{2}$ & $(2-1)^{2}$ & sulistyo \\
\hline 9 & $(3-5)^{2}$ & $(2-4)^{2}$ & $(3-1)^{2}$ & $(1-2)^{2}$ & $(5-2)^{2}$ & $(2-2)^{2}$ & $(2-2)^{2}$ & Danu \\
\hline 10 & $(3-3)^{2}$ & $(2-4)^{2}$ & $(3-3)^{2}$ & $(1-2)^{2}$ & $(5-5)^{2}$ & $(2-2)^{2}$ & $(2-2)^{2}$ & Arifin \\
\hline 11 & $(3-3)^{2}$ & $(2-4)^{2}$ & $(3-2)^{2}$ & $(1-2)^{2}$ & $(5-5)^{2}$ & $(2-2)^{2}$ & $(2-2)^{2}$ & Suryanto \\
\hline 12 & $(3-3)^{2}$ & $(2-3)^{2}$ & $(3-2)^{2}$ & $(1-2)^{2}$ & $(5-4)^{2}$ & $(2-2)^{2}$ & $(2-2)^{2}$ & Surono \\
\hline 42 & $(3-1)^{2}$ & $(2-2)^{2}$ & $(3-3)^{2}$ & $(1-6)^{2}$ & $(5-3)^{2}$ & $(2-3)^{2}$ & $(2-1)^{2}$ & Agus \\
\hline
\end{tabular}

Berdasarkan rumus 1. diatas, selanjutnya dihasilkan euclidean sebagai berikut :

Tabel 6. Euclidean

\begin{tabular}{crl}
\hline & & Nama \\
No. & Euclidean & Teknisi \\
\hline 1 & 2,83 & Agus \\
2 & 4,69 & Danu \\
3 & 2,24 & Arifin \\
4 & 2,65 & Suryanto \\
5 & 2,45 & sulistyo \\
6 & 2,24 & Surono \\
7 & 3,16 & Ismadi \\
8 & 2,83 & sulistyo \\
9 & 4,69 & Danu \\
10 & 2,24 & Arifin \\
11 & 2,45 & Suryanto \\
12 & 2,00 & Surono \\
$\cdot$ & & \\
. & & \\
42 & 5,92 & Agus \\
\hline
\end{tabular}

\section{d. Pengurutan Euclidean}

Setelah euclidien tiap-tiap aktivitas jumlahnya ditemukan, maka selanjutnya melakukan pengurutan dari nilai euclidean terkecil sampai terbesar, dengan hasil seperti berikut :

Tabel 7. Pengurutan Euclidean Secara Ascending 


\begin{tabular}{|c|c|c|}
\hline No. & Euclidean & $\begin{array}{l}\text { Nama } \\
\text { Teknisi }\end{array}$ \\
\hline 12 & 2,00 & Surono \\
\hline 3 & 2,24 & Arifin \\
\hline 6 & 2,24 & Surono \\
\hline 10 & 2,24 & Arifin \\
\hline 5 & 2,45 & sulistyo \\
\hline 11 & 2,45 & Suryanto \\
\hline 4 & 2,65 & Suryanto \\
\hline 19 & 2,65 & Surono \\
\hline 8 & 2,83 & sulistyo \\
\hline 1 & 2,83 & Agus \\
\hline 16 & 3,00 & Arifin \\
\hline 7 & 3,16 & Ismadi \\
\hline 13 & 3,16 & Ismadi \\
\hline 17 & 3,16 & Suryanto \\
\hline 18 & 3,16 & sulistyo \\
\hline 14 & 3,32 & Agus \\
\hline 20 & 3,46 & Ismadi \\
\hline 25 & 3,61 & Surono \\
\hline 24 & 3,74 & sulistyo \\
\hline 21 & 3,87 & Arifin \\
\hline 23 & 3,87 & Suryanto \\
\hline
\end{tabular}

\begin{tabular}{rrl}
\hline \multicolumn{1}{l}{ No. } & Euclidean & Teknisi \\
\hline 26 & 4,24 & Ismadi \\
34 & 4,47 & Surono \\
28 & 4,58 & Arifin \\
29 & 4,58 & Suryanto \\
2 & 4,69 & Danu \\
9 & 4,69 & Danu \\
33 & 4,69 & sulistyo \\
30 & 4,90 & Agus \\
31 & 4,90 & Agus \\
27 & 5,00 & Ismadi \\
15 & 5,10 & Danu \\
38 & 5,29 & Surono \\
40 & 5,48 & Arifin \\
22 & 5,57 & Danu \\
37 & 5,57 & Suryanto \\
41 & 5,66 & sulistyo \\
39 & 5,74 & Agus \\
35 & 5,92 & Ismadi \\
42 & 5,92 & Agus \\
32 & 6,16 & Danu \\
36 & 6,86 & Danu \\
\hline
\end{tabular}

e. Pemilihan hasil

Pemilihan hasil adalah berdasarkan penentuan nilai $\mathrm{k}$ (jumlah tetangga terdekat), pada penelitian ini akan dicari nilai $\mathrm{k}$ dengan hasil pemilihan yang sama atau mendekati nilai manual.

Jika pada data uji dengan urutan ke- 43 secara manual dan dihasilkan nama teknisi yang direferensikan adalah "surono"

\begin{tabular}{rlrllrlll}
\hline & Tk. & Lama & Bidang & Jenis & & Tingkat & Tk. & Nama \\
No. & Pendidikan & Kerja & Keahlian & Kerusakan & Usia & Kerusakan & Ketuntasan & Teknisi \\
\hline 43 & 3 & 2 & 3 & 1 & 5 & 2 & 2 & surono \\
\hline
\end{tabular}

Maka selanjutnya metode $K$-Nearest Neighbor mencari frekwensi kemunculan masing-masing tenaga teknisi dan persentase kemunculannya dengan uji nilai $\mathrm{k}=3,5,7,9,11,13$ berdasarkan dari hasil tabel 7.

Pada uji nilai $\mathrm{K}=3$ dihasilkan persentase kemunculan nama Surono sebanyak $66 \%$, uji nilai $\mathrm{k}=5$ dengan persentase kemunculan $40 \%$, $\mathrm{k}=7$ dengan persentase kemunculan $29 \%$, $\mathrm{k}=9$ dengan persentase kemunculan $33 \%, \mathrm{k}=11$ dengan dengan persentase kemunculan $27 \%$ dan $\mathrm{k}=13$ dengan persentase kemunculan $23 \%$.

\section{Kesimpulan}

Hasil klasifikasi dari metode $K$-Nearest Neighbor mampu memberikan referensi hasil yang sama dengan hasil pehitungan manual.

Pada hasil diatas menunjukkan bahwa persentase kemunculan nama yang direfensikan menempati persentase tertinggi yaitu $66 \%$ dengan nilai $\mathrm{k}=3$, sehingga $\mathrm{k}=3$ sesuai untuk proses referensi tenaga teknisi 


\section{Daftar Pustaka}

[1] F. A. Lestari Niu, L. Kalangi and L. Lambey, "Analisis Pengelolaan Aset Pemerintah Daerah Kabupaten Bolaang Mongondow," Jurnal EMBA (Jurnal Riset Ekonomi, Manajemen, Bisnis dan Akuntansi, vol. 1, pp. 160-170, 2019.

[2] A. R. Kusuma Dewi and A. P. Nugraheni, "Pengelolaan Aset/Barang Milik Daerah di Dinas Tenaga Kerja Kota Magelang Tahun 2018/2019," Jurnal Ilmiah MEA (Manajemen, Ekonomi dan Akuntansi), vol. 4, pp. 761-776, 2020.

[3] A. C. Kirana, "Sistem Pendukung Keputusan Menentukan Teknisi Mesin Edc (Electronic Data Capture) Terbaik Menggunakan Metode Analytical Hierarchy Process (Studi Kasus : Pt. Souci Indoprima)," Pelita Informatika Budi Darma, vol. 9, pp. 7-15, April 2017.

[4] T. Abeywickrama, "kNearest Neighbors on Road Networks: A Journey in Experimentation and InMemory Implementation Technical Report," Faculty of Information Technology, Monash University, Australia, pp. 1-18, Agustus 2016.

[5] Y. F. Safri, R. Arifudin and M. A. Muslim, "K-Nearest Neighbor and Naive Bayes Classifier Algorithm in Determining The Classification of Healthy Card Indonesia Giving to The Poor," Scientific Journal of Informatics, vol. 5, pp. 9-18, Mei 2018.

[6] Y. Widiastuti, "Decision Support System For House Purchasing Using Knn (K-Nearest Neighbor) Method," Jurnal ITSSMART, vol. 5, pp. 43-49, 2016.

[7] W. Lishan, "Research and Implementation of Machine Learning Classifier Based on KNN," pp. 1-5, 2019.

[8] A. Bode, "K-Nearest Neighbor Dengan Feature Selection Menggunakan Backward Elimination Untuk Prediksi Harga Komoditi Kopi Arabika," ILKOM, vol. 9, pp. 188-195, 2017.

[9] A. Setiawan and A. winarno, "Prioritas Pengemudi Untuk Kenyamanan Layanan Penumpang Di Lingkungan Akademik Berbasis K-Nearest Neighbor," Dinamika Rekayasa, vol. 16, pp. 33-40, 2020.

[10] Z. Cheng, "An Improved KNN Classification Algorithm based on Sampling," Advances in Engineering Research, vol. 114, pp. 220-225, 2017.

[11] A. Karim, "Sistem Pendukung Keputusan Penerimaan Teknisi Baru Pada PT Maris Utama Di Jakarta," Jurnal Sisfotek Global, vol. 1, pp. 114-123, 2017.

[12] N. L. G. Pivin Suwirmayanti, "Penerapan Metode K-Nearest Neighbor Untuk Sistem Rekomendasi Pemilihan Mobil," Techno.COM, vol. 15, pp. 120-131, 2017.

[13] M. A. Banjarsari, "Penerapan K-Optimal Pada Algoritma Knn untuk Prediksi Kelulusan Tepat Waktu Mahasiswa Program Studi Ilmu Komputer Fmipa Unlam Berdasarkan IP Sampai Dengan Semester 4," KLIK, vol. 2, pp. 51-64.

[14] G. Guo, "KNN Model-Based Approach in Classification," pp. 1-13, 2018.

[15] J. I. Kartika, "Penentuan Siswa Berprestasi Menggunakan Metode K-Nearest Neighbor dan Weighted Product (Studi Kasus : SMP Negeri 3 Mejayan)," Jurnal Pengembangan Teknologi Informasi dan Ilmu Komputer, vol. 1, pp. 352-360, 2017. 